\title{
Comment
}

\section{Metodologias Ativas na Disciplina Ética Médica: Promoção da Autonomia e Prevenção do Erro Médico}

\author{
Maria Teresa de Vasconcelos Sobral ${ }^{1}$; Symara Abrantes Albuquerque de Oliveira Cabral ${ }^{2}$; Eitan Naamam Berezim ${ }^{3}$; \\ Maria Carmem Batista de Alencar ${ }^{4}$; Francileuda Batista de Almeida ${ }^{5}$
}

Resumo: A metodologia ativa proporciona a aprendizagem a partir do desenvolvimento da autonomia do sujeito, a partir das mudanças metodológicas o docente, focado na problematização, como facilitador de aprendizagem, passa a tornar-se coadjuvante no processo educacional, estimulando a autonomia do sujeito-aluno. Tais perspectivas ancoram-se no princípio teórico significativo na autonomia explícita por Paulo Freire. Trata-se de um estudo descritivo, exploratório com abordagem qualitativa e quantitativa dos dados, objetivando analisar os índices de erros médicos, bem como, rever as atuais metodologias de ensino empregadas da disciplina de ética médica e, assim, sugerir implementação da estrutura de ensino da disciplina de ética médica baseando-se no código de ética e na legislação médica nos cursos de medicina do país.

Palavras-chave: Ensino; Ética Médica; Educação Médica; Metodologias Ativas.

\section{Active Methodologies in Medical Ethics Course: Promoting Autonomy and Prevention of Medical Error}

\begin{abstract}
The active methodology provides the learning from the development of the autonomy of the subject, from the methodological changes the teacher, focused on the problematization, as a facilitator of learning, starts to become auxiliary in the educational process, stimulating the autonomy of the subject- student. Such perspectives are anchored in the significant theoretical principle in explicit autonomy by Paulo Freire. This is a descriptive, exploratory study with a qualitative and quantitative approach, aiming at analyzing the indexes of medical errors, as well as reviewing the current teaching methodologies employed in the discipline of medical ethics and, thus, suggesting the implementation of the teaching structure of the discipline of medical ethics based on the code of ethics and medical legislation in the medical courses of the country.
\end{abstract}

Keywords: Teaching; Medical Ethics; Medical Education; Active Methodologies.

\footnotetext{
${ }^{1}$ Graduação em Medicina pela Faculdade de Ciências Médicas de Pernambuco. Especialização em Ginecologia e Obstetrícia pelo Federação Brasileira das Sociedades de Ginecologia e Obstetrícia - SP. Especialização em Preceptoria de Residência Médica no SUS pelo Instituto SírioLibanês de Ensino e Pesquisa. Especialização em Saúde da Mulher pela Faculdade Integrada do Ceará e Especialização em Saúde da Família2005 pela Universidade Federal da Paraíba;

${ }^{2}$ Graduação em Enfermagem pela Universidade Federal de Campina Grande. Mestre em Sistemas Agroindustriais pela Universidade Federal de Campina Grande. Cursando Doutorado em Ciências da Saúde pela Faculdade de Ciências Médicas da Santa Casa de São Paulo - SP. Autora correspondente: symara_abrantes@hotmail.com;

${ }^{3}$ Programa de Pós-Graduação em Ciências da aSaúde da Faculdade de Ciências Médicas da Santa Casa de São Paulo, FCMSCSP, Brasil;

${ }^{4}$ Mestrado Acadêmico em Sistemas Agroindustriais pela Universidade Federal de Campina Grande. Mestrado Profissional em Saúde Publica pela Universidad Tecnológica Intercontinental. Especialização em Preceptoria em Residência no SUS pelo Sírio Libanês. Especialização em Saúde Pública pela Faculdade São Francisco da Paraíba. Especialização em Saúde da Família pela Faculdade Integrada de Patos. Especialização em Enfermagem do Trabalho pela Faculdade Integrada de Patos. Graduação em Enfermagem pela Universidade Federal de Campina Grande. Docente da Graduação em Enfermagem da Faculdade São Francisco da Paraíba;

${ }^{5}$ Bacharelado em Farmácia pela Faculdade Santa Maria de Cajazeiras. Atualmente é diretor (a) técnico (a) - Farmacia Santa Maria. Especialista em Analises Clínicas pela Faculdade Leão Sampaio em Juazeiro do Norte -CE. Pós Graduação Lato sensu em Atenção Farmaceutica e Farmacologia Clínica pelo CAS/IPOG.
} 


\section{Introdução}

A metodologia ativa tem objetivo à aprendizagem como um processo, no qual o professor atua como facilitador de modo a estimular a problematização, de modo que o discente aprende fazendo, o que são consideradas as melhores estratégias para aquisição do conhecimento, uma vez que baseia-se em aprender a aprender, aprender a fazer, e aprender a trabalhar em grupo, num processo permanente, no qual o aluno é o sujeito atuante na sua própria aprendizagem, sendo criativo, dinâmico, responsável, interessado, desenvolvendo sua capacidade de análise, habilidades de síntese, de planejamento, ou seja, sua metacognição e deste modo, superando o aprendizado adquirido através das aulas teóricas, das demonstrações, das leituras, que são consideradas estratégias educacionais tradicionais em que o aluno se torna um simples receptor de conteúdos pré-elaborados pelo professor, o que estimula o desenvolvimento da autonomia do sujeito (PETTA, et al., 2015).

As metodologias ativas são alicerçadas em um princípio teórico significativo na autonomia explícita na inovação de Paulo Freire, de modo que o discente pode desenvolver a auto didática, a partir da capacidade de formação através de uma relação na qual autores envolvidos experimentam de um reconhecimento mútuo, geralmente discentes e docentes que utilizam a problematização como estratégia de ensino e aprendizagem, com o objetivo de alcançar a motivação, cabendo a eles uma atitude favorável para a aprendizagem, o que requer mudança de atitude por parte do docente no permanente exercício da reflexão, da mudança de perspectiva para o acompanhamento a partir de responsabilidade proativa na articulação do ato de ensinar e aprender (MITRE, 2008).

Como resultado de discussões realizadas no âmbito da Especialização em Preceptoria Médica promovida pelo Hospital Sírio Libanês, que utiliza a metodologia ativa de forma intrínseca ao aprendizado, surgiram as problemáticas: como estão sendo formados os estudantes de medicina quanto a responsabilidade ética? Como estão sendo administradas as aulas sobre ética no curso de medicina? Qual a importância que está sendo dada a esta disciplina e como ela pode evitar que o futuro médico cometa o erro de imperícia, imprudência e negligencia? Como o ensino, através de metodologias ativas, pode sensibilizar estes alunos para uma prática transformadora, ética e responsável, tornando-os de excelência na sua profissão? Como os 
professores atuam no processo de ensino na cadeira de ética médica?

Neste escopo, identificando a necessidade de uma melhor aprendizagem no ensino médico quanto a ética, o estudo pretende, através de uma abordagem descritiva, analisar os índices de erros médicos registrados no tribunal superior de justiça e junto ao Conselho Federal de Medicina, bem como, rever as atuais metodologias de ensino empregadas da disciplina de ética médica baseada nas ementas das faculdades de medicina de um município do interior paraibano, e sugerir implementação da estrutura de ensino da disciplina de ética médica baseando-se no código de ética e na legislação médica nos cursos de medicina do país, a partir do emprego das metodologias ativas com o objetivo de sensibilizar o aluno quanto situação de sofrimento físico, emocional e social que se encontra o paciente, para que o futuro médico, portanto, tenha dedicação e responsabilidade quanto a vida que está em seu encargo e consequentemente, haja melhoria do desempenho prático na área de atuação, objetivando, por fim, a redução nos índices de erro médico por imperícia, imprudência e negligência.

\section{Metodologia}

Metodologicamente, trata-se de um estudo descritivo, exploratório com abordagem qualitativa e quantitativa dos dados, utilizando por base estudo qualitativo de referencial científico já publicado, dados quantitativos fundamentais à problemática e arcabouço legal referente à educação médica e ao exercício da medicina.

\section{Resultados e Discussões}

A educação médica brasileira vem passando por mudanças nos últimos anos e muito se tem discutido a respeito. O Ministério da Saúde, através da resolução número 3 de 20 de junho de 2014, instituiu as Diretrizes Curriculares Nacionais do curso de Graduação em Medicina, para que o médico possa atuar nos diferentes níveis de atenção à saúde. Conforme as diretrizes curriculares nacionais do curso de medicina, o aluno deve ter uma formação geral e humanística, crítica reflexiva, ética com capacidade para atuar na promoção, prevenção, 
recuperação e reabilitação, com responsabilidade social e compromisso com a saúde integral (BRASIL, 2014).

Faz parte das diretrizes, conforme artigos 29, 32 e 34 a utilização das metodologias ativas e manutenção permanente de programa de formação e desenvolvimento da docência em saúde com domínio em metodologias ativas pautadas em práticas multidisciplinares, incluindo dimensões éticas humanísticas e de direitos humanos (BRASIL, 2014).

De acordo com Chiarella et all. (2015), tomando por base os princípios norteadores da política nacional de humanização, os professores de saúde precisam passar a valorizar a dimensão subjetiva e social que constituem o escopo biopsicossocial dos indivíduos, e que estas políticas de educação encontram apoio na linha pedagógica de Paulo Freire. A respeito desta metodologia problematizadora, Marim et all. (2010), refere que este processo foi defendido por Paulo freire e tendo como referência os estudos de Bordenave e Pereira, e no arco de Maguerez, cujos pontos chaves são observação, identificação do problema, contextualização, hipótese, solução e aplicação da realidade, buscando estimular a observação e análise dos fatos e priorizando uma conduta ativa do discente e professor no processo de aprendizagem, desestimulando práticas como a concepção bancária da educação, citada por Paulo Freire na qual o professor é o sujeito da ação, detentor de conhecimento e o aluno um sujeito passivo, receptor de informações, cuja forma de orientação baseia-se na opressão e subjugação.

Importante salientar que de acordo com Freire (2014), “[...] não foi a educação que fez mulheres e homens educáveis, mas a consciência de sua inconclusão é que gerou sua educabilidade [...]" (p.57). Compreender-me dentro de um processo transformador possibilita a autorreflexão constante e a percepção de tudo aquilo que precisa ser transformado em metas e que alimentam a esperança, e assim acreditar que "[...] minha presença no mundo não é a de quem a ele se adapta, mas a de quem nele se insere [...]" (p.53), e assim “[...] gosto de ser gente porque, inacabado, sei que sou um ser condicionado, mas, consciente do inacabamento, sei que posso ir mais além dele [...]" (p.52-53).

Deste modo, observando as ementas do curso de medicina nas disciplinas de ética das faculdades locais constatou-se que as metodologias utilizadas, tanto para ensino como para avaliação, são ainda, em grande parte, a tradicional, na qual o professor ensina e o aluno assiste a aula, sendo unicamente detentor de saber e a avaliação através de prova, tendo toda a disciplina apenas o tempo disponível de trinta horas e dois créditos. 
Para uma boa formação médica é importante contemplar problemas éticos da profissão e desenvolver aprendizagem que possibilite o desenvolvimento ético no aluno, tanto a nível individual quanto coletivo. É fundamental refletir que a conduta do futuro médico se inicia na vida universitária, nos espaços de estudo, funcionando como local para aprendizagem técnica, mas também ética acerca de suas condutas.

Segundo Rios (2009), algumas escolas médicas brasileiras colocam disciplinas de humanidades médicas em currículo de graduação e, embora essenciais para uma boa prática profissional, para muitos alunos e professores as disciplinas de humanidades são tidas como prescindíveis e desinteressantes. Nas aulas práticas, realizadas nos postos de saúde, hospital e em simulações através o OSCE (Objective Structured Clinical Examination), a formação ética e moral ainda é precária, a abordagem social dos problemas relacionados a saúde não causam ânimo entre os estudantes, sendo mais desenvolvido atividades ligadas as diversas clínicas, o que vai interferir nos valores éticos profissionais no cotidiano do futuro médico que acarretará em consequência danosas ao profissional, pacientes e sociedade.

Segundo Ferreira (2009) ética é definida como o estudo que investiga os juízos de apreciação referente a conduta humana do ponto de vista do bem e do mal, e moral "é um conjunto de regras de conduta ou hábitos julgados válidos, quer universalmente, para grupo ou pessoal determinada".

Refere Raul; Canal (2016), que

O que temos visto, hoje em dia, nos médicos novos é que se tratam de profissionais com muita informação porem com pouca formação. Recebem informações nas bancas escolares, mas não tem formação suficiente para lidar com tais informações. São médicos preparados para cuidar de doenças e não de doentes.

O médico, pautando suas atividades nas ações técnicas, são frequentemente desatentos às regras de convivência profissional e comportamental, demandando situações que poderão causar problemas para si e para os pacientes. Em sua busca apenas por conhecimento técnico, deixa a desejar o conhecimento da ética profissional e da justiça.

O Superior Tribunal de Justiça registrou no primeiro trimestre de 2014 que foram julgados 300\% de recursos sobre erro médico. De 2011 a 2014, o crescimento foi de 100\%. Quanto a origem dos processos o Rio de Janeiro é o campeão dos recursos, detendo 25,69\%. A Paraíba com 0,83\%. Dos processos que chegam ao S.T.J. 59,35\% dos autores das denúncias 
são mulheres. Quanto ao gênero do médico responsável pelo ato profissional que demanda o processo, os homens representam $87,5 \%$ dos processados. Das especialidades com mais demanda no T.S.J. (Tribunal Superior de Justiça) a ginecologia e obstetrícia encontra-se no primeiro lugar e o dano de morte foi a campeã das reclamações.

Buscas junto ao Conselho Federal de Medicina, com dados fornecidos pelo próprio conselho após solicitação formação revelam que, entre 2010 e 2014 foram registradas 638 penalizações por erro médico (Conforme Lei n ${ }^{\circ} 3.268$, de 30 de setembro de 1957), destas $38 \%$ na especialidade Ginecologia e Obstetrícia, 25\% em Clínica Médica, 14\% na Pediatria, 13\% em Cirurgia Plástica e 10\% em Cirurgia Geral.

Gomes e França (1998), definem erro médico como dano provocado pela ação ou inação de médico no exercício da profissão e sem a intenção de cometê-lo, que acontece por imprudência, imperícia e negligencia sendo o mal provocado pelo médico, considerado culposo devido a não ter havido intenção de matar. Negligencia é erro por desatenção quando o médico não oferece o devido cuidado ao paciente; imperícia quando o médico realiza um procedimento sem estar preparado. Imp3rudência quando assume o risco ao colocar em perigo o paciente através de conduta sem amparo científico.

\section{Considerações Finais}

As metodologias ativas, ancorando-se na Pedagogia da Autonomia e na educação problematizadora de Paulo Freire, podem ser utilizadas para a melhoria da disciplina de ética das faculdades, com a possibilidade de usar as seguintes técnicas como: distribuição dos alunos em pequenos grupos para que haja uma participação mais efetiva; usar narrativas vivenciadas ou observadas pelos alunos durante seus estágios ou vivenciada por algum membro familiar do discente; simulação de atendimento através do OSCE, enfatizando o aspecto social emocional do paciente; discussão de caso clínico no qual houve falha da atenção e comunicação com o paciente; oficina com simulação de julgamento, TBL, situação problema, cine viagens para análise crítica reflexiva quanto a ética. Nas práticas clínicas fortalecer a importância da anamnese do paciente quando ao seu aspecto emocional e social e a sua necessidade de apoio.

É relevante que em todas as disciplinas, mesmo que o professor tenha dificuldade em 
aplicar metodologias ativas, porém que faça parte das práticas dos alunos, nos estágios nas unidades básicas de saúde e nos hospitais, o incentivo e compromisso com a formação ética não só abordando seus próprios valores moral e ético como também incentivando o egresso a fazêlo.

A ausência ou pouca oferta de horas aulas e créditos das disciplinas relacionadas a ética, a humanização, a responsabilidade moral, civil penal são preocupantes e fora da realidade, uma vez que estes conhecimentos são necessários para a formação e o atendimento médico com qualidade em todas as especialidades. É urgente a necessidade de motivação e dinamismo nestas disciplinas de forma articulada, possibilitando ao aluno fazer suas reflexões críticas para que ele chegue a observar que faz parte do contexto, entendendo sua participação e contribuição social. A prática da medicina é diretamente influenciada pelo ensino médico, necessitando de uma atenção e dedicação maior sobre esta formação, especialmente na educação continuada da relação médico-paciente e, assim, buscar a redução da ocorrência de erros e processos éticos médicos.

\section{Referências}

BRASIL. Ministério da Educação Conselho Nacional de Educação. Câmara de Educação Superior. Resolução No 3, de 20 de Junho De 2014. Brasília, 2014.

CHIARELlA, T. et al. A Pedagogia de Paulo Freire e o Processo Ensino-Aprendizagem na Educação Médica. Rev. bras. educ. med. [online]. 2015, vol. 39, n. 3, pp. 418-425.

FERREIRA, A.B.H. Miniaurélio: o dicionário da língua portuguesa. 7. ed. rev. atual. Curitiba: Positivo; 2008.

GOMES, J.C.M.; FRANÇA, G.V. Erro Médico. In.: COSTA, S.I.F.; OSELKA, G.; GARRAFA, V. Iniciação à bioética. Brasília: Conselho Federal de Medicina, 1998. Parte IV - Bioética Clínica, p. 243-256.

MARIN, M.J.S. et al. Aspectos das fortalezas e fragilidades no uso das metodologias ativas de aprendizagem. Rev. bras. educ. med. [online]. 2010, vol. 34, n. 1, pp. 13-20. .

MITRE S.M. e al. Metodologias ativas de ensino-aprendizagem na formação profissional em saúde: debates atuais. Revista Ciência \& Saúde Coletiva, 13(Sup 2):2133-2144, 2008. 
PETTA, H. L. et al. Preceptoria do SUS: caderno do curso 2015. São Paulo: Ministério da Saúde; Instituto Sírio Libanês de Ensino e Pesquisa, 2015. 51 p. (projetos de apoio ao SUS).

REGO, S.; GOMES, A.P.; SIQUEIRA-BATISTA, R. Bioética e humanização como temas transversais na formação médica. Rev. bras. educ. med. [online]. 2008, vol. 32, n. 4, pp. 482491.

RIOS, I.C. Humanização: a essência da ação técnica e ética nas práticas de saúde. Rev. bras. educ. med. [online]. 2009, vol. 33, n. 2, pp. 253-261.

\section{Como citar este artigo (Formato ABNT):}

SOBRAL, Maria Teresa V.S.; CABRAL, Symara A.A.O.; BEZEZIM, Eitan N.; ALENCAR, Maria Carmem B.; ALMEIDA, Francieuda B. Metodologias Ativas na Disciplina Ética Médica: Promoção da Autonomia e Prevenção do Erro Médico. Id on Line Revista Multidisciplinar e de Psicologia, Julho de 2017, vol.11, n.36, p.104-111. ISSN: 1981-1179.

Recebido: 16.06 .2017

Aceito: 19.06 .2017 